\title{
Hydrological dispersion module of JRODOS: renewed chain of the emergency response models of radionuclide dispersion through watersheds and rivers
}

\author{
M. Zheleznyak ${ }^{1,2}$, S. Kivva ${ }^{1,3}$, I. Ievdin ${ }^{1}$, O. Boyko ${ }^{1,3}$, P. Kolomiets ${ }^{1}$, M. Sorokin ${ }^{1,3}$, O. Mikhalskyi ${ }^{1}$ \\ and D. Gheorghiu ${ }^{4}$ \\ ${ }^{1}$ Ukrainian Center of Environmental and Water Projects (UCEWP), Kiev, Ukraine. \\ 2 Fukushima University, Fukushima, Japan. \\ ${ }^{3}$ Insitute of Mathematical Machines \& Systems Problems of National Academy of Sciences of Ukraine (IMMSP), Kiev, Ukraine. \\ ${ }^{4}$ Horia Hulubei National Institute for R\&D in Physics and Nuclear Engineering (IFIN-HH), Bucharest, Romania.
}

\begin{abstract}
Hydrological Dispersion Module (HDM) of JRODOS includes the chain of the models describing the washing out of the accidental deposition from the watersheds to rivernet and radionuclide transport in rivers and reservoirs. This modelling chain of HDM was renewed by the integration of two models. One-dimensional model RIVTOX_SV provides possibilities for the computing radionuclide transport in the branched river networks. Twodimensional model for shallow reservoirs and river floodplains COASTOX_UN used algorithms of the parallel computing on the unstructured mesh of the finite volume method. The renewed modelling chain was tested for the subwatersheds of the Danube river and the Dnieper river.
\end{abstract}

Keywords: radionuclide / dispersion in river basins / model / decision support / JRODOS

\section{Introduction}

The Hydrological Dispersion Module (HDM) has been included into the real-time online decision support system (DSS) for offsite nuclear emergency management RODOS to simulate the radionuclide transport in surface waters (Heling et al., 1997). A deposition field simulated by the Atmospheric Dispersion Module (ADM) of RODOS or a direct accidental release of radionuclides to water bodies are used as the input data for HDM modelling. The first versions of the RODOS software integrating the models with the databases, GIS and user interfaces were developed in 90s-beginning of 2000s under HPUX X-Windows. The first version of HDM for JRODOS - the multiplatform "user friendly" version of RODOS developed within EC EURANOS has integrated the model of radionuclide wash-off from the watersheds RETRACE_R, one-dimensional model RIVTOX of river radionuclide transport and Foodchain Dose Module Aquatic (Zheleznyak et al., 2010). Within the EC PREPARE project HDM-JRODOS is extended to include the marine contamination models (Bezhenar et al., 2016) and the models for the assessment of the long-term fate of radionuclides and the efficiency of the remediation measures in rivers and lakes. The development of the renewed model chain of radionuclide dispersion through watersheds and rivers for the initial postaccidental period was recommended by the RODOS User Group after the testing of the JRODOS-HDM to make it applicable for the modelling of the branched river networks and river floodplains. The paper describes briefly this renewed modelling chain of JRODOS and its testing for the Dnieper river and Danube river.

\section{Models and software}

RIVTOX_SV is new version of one-dimensional model RIVTOX describing the river flow, suspended sediment transport and radionuclide transport in solute and transport of radionuclides adsorbed by suspended sediments. The river hydraulic module is based on the numerical solution of the full version of the Saint Venant equation instead of the numerical solution of the diffusive wave approximation of the Saint Venant equation used in the previous version of RIVTOX in RODOS (Zheleznyak et al., 1993, 2010). The numerical algorithm of RIVTOX_SV is based on the method for the calculations on the branched river networks that was successfully tested in the hydraulic code CHARIMA (Holly et al., 1990). The conjugate gradient method is used for the numerical solution of the algebraic equations that are obtained by the applying of the double sweep technique to the system of the nonlinear algebraic equations connecting all computational nodes the river network as a discrete form Saint Venant equation in the four-point implicit finite-difference scheme (Cunge et al., 1980) The sediment and radionuclide transport equations were descretised by the same finite-difference scheme.

COASTOX_UN is new more computationally efficient version of COASTOX code (Zheleznyak et al., 1992; Monte et al., 2006) that includes two-dimensional (depth averaged) 


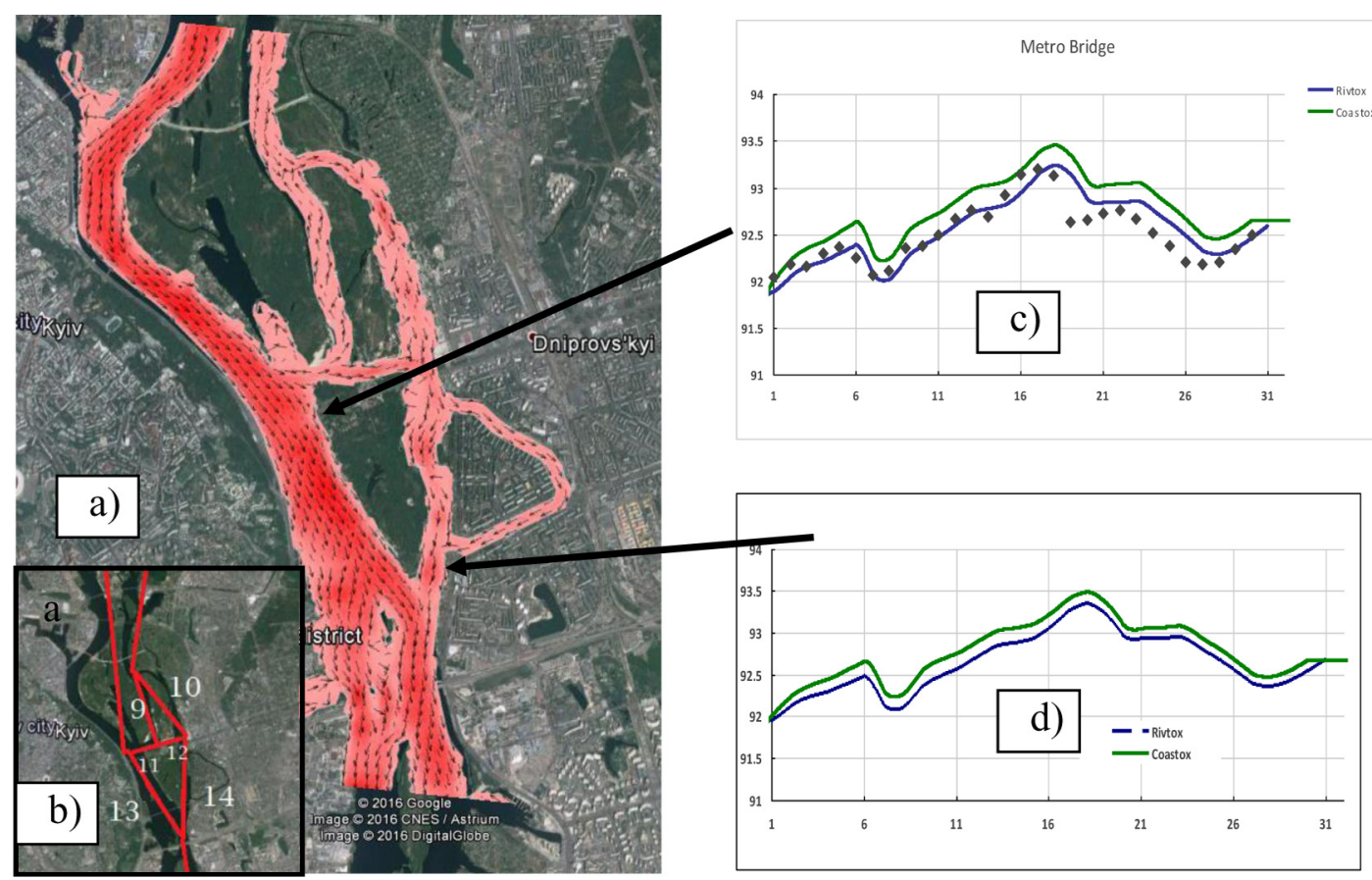

Figure 1. (a) Dnieper river velocities field at Kiev modelled by COASTOX_UN at the maximum of the spring flood 2010 shown on the Google Maps background. (b) The river net schematization of RIVTOX_SV. (c) and (d) Water elevation dynamics within 30 days at flood maximum computed by COASTOX_UN (green line) and RIVTOX_SV (blue line) for two locations.

model of open flow hydrodynamics, the submodels of the suspended sediment and radionuclide transport is shallow water bodies. The numerical solution of the COASTOX_UN is based on the descretization of the shallow water equations of the open flow hydrodynamics and 2D equations of advective-diffusive transport of suspended sediment and radionuclides on the unstructured triangular grid by the finite volume method. The algorithms of the parallel computations based on the split of the computational area to the set of the domains was implemented to increase the computational performance of the model. RIVTOX_SV and COASTOX_UN were integrated into the JRODOS-HDM on the basis the technology of the distributed objects-wrappers (Ievdin et al., 2010). RIVTOX_SV receives the lateral inflow of radionuclides to river canals from the watershed RETRACE_R model (Zheleznyak et al., 2010).

\section{Testing and applications}

The hydrodynamics modules of COASTOX_UN and RIVTOX_SV were tested versus the data observed at the branches of the Dniper river network near Kiev during the high spring flood 2010 (Figure 1). The results of simulations of both models and the data measured at the water gage station "Metro Bridge" (Figure 1c) are in a reasonable agreement. The renewed RIVTOX_SV model was tested also for the complicated branched river network of the Danube river (Figure 2a) at the Cernavoda NPP (CNPP). The model calibration versus the data of the nine Romanian water gage stations at CNPP shows possibilities of RIVTOX_SV to simulate hydrodynamics of this branched river network flow with a good accuracy (e.g., Figure 2b).
The stress test scenario for CNPP was used in the assumption of the 89 hours atmospheric release of the permanent rate due to the CNPP Blackout. The simulated by the JRODOS ADM fallout (Figure 2c) was used by the chain of RETRACE-RIVTOX models to simulate the radionuclide transport through the Danube river network (Figure 2d,e). The calculated by RIVTOX radionuclide fluxes from the Danube branches to the Black Sea were used to calculate) the contamination of the Black sea water, sediment and biota by POSEIDON model (Bezhenar et al., 2016).

\section{Conclusions}

An important component of the extension of HDM of JRODOS within EC PREPARE Project is the renewal of the modeling chain of radionuclide dynamics in the rivers and reservoirs for the initial short term and intermediate term postaccidental periods. The possibilities for the computations of the radionuclide transport in a branched river network are introduced into HDM by the replacement RIVTOX by RIVTOX_SV-new computationally efficient one-dimensional model. The radionuclide dispersion in shallow reservoirs and river floodplains is introduced into JRODOS-HDM by the integration into it the two-dimensional model COASTOX_UN which computational performance is based on the implementation of the unstructured mesh finite volume scheme and parallel computing. The renewed modelling chain was tested for the Dnieper River at Kiev and the Danube river at Cernavoda NPP. The integration of these models into the JRODOS HDM within EC PREPARE project extends HDM applicability for the forecasting of the rivers and reservoirs contamination after the nuclear accidents and for the 


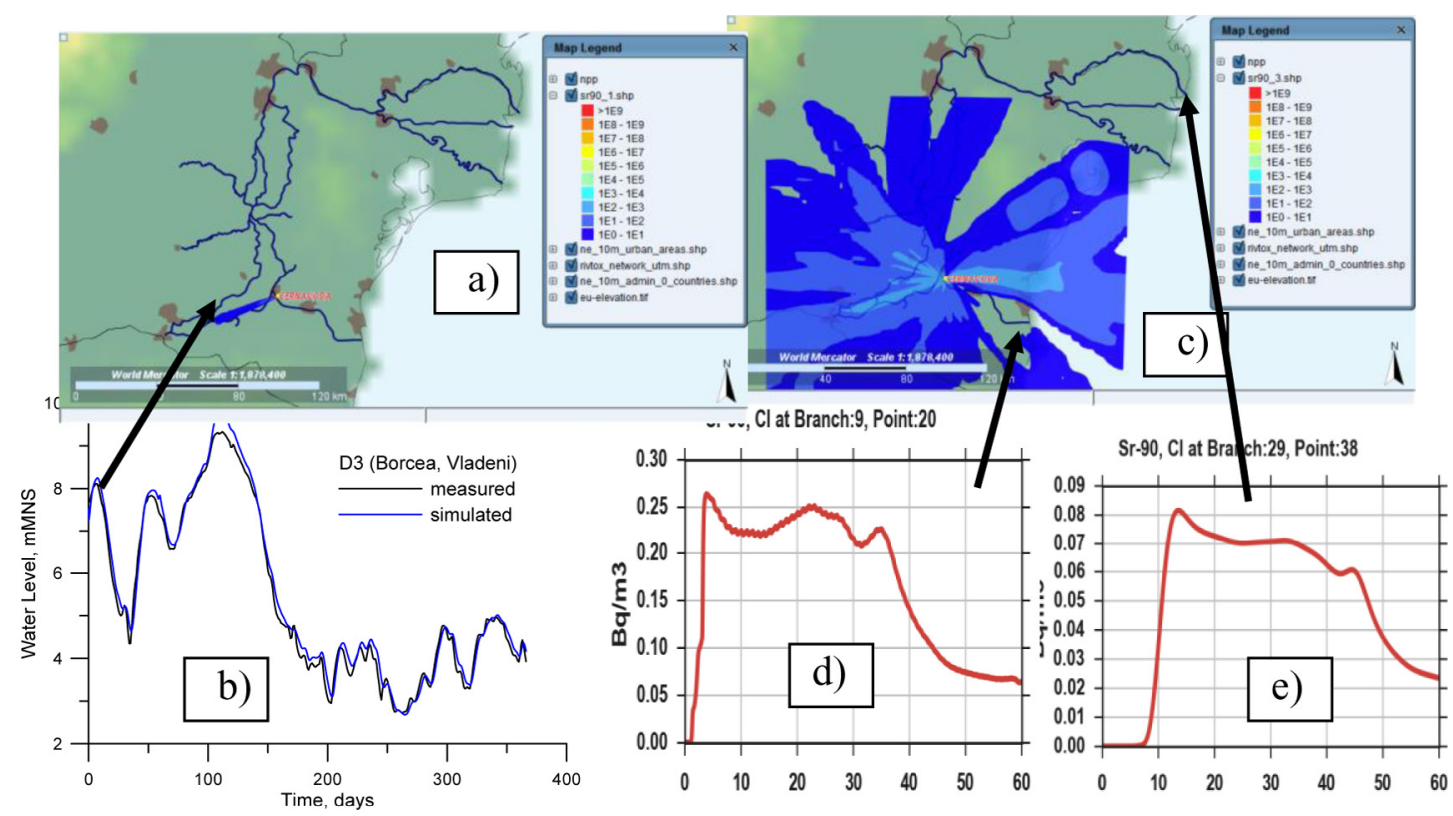

Figure 2. (a) Lower Danube river network in JRODOS HDM window and ${ }^{90} \mathrm{Sr}$ deposition from CNPP. (b) Comparison of measured and simulated water elevation at the water gage Borsea Vladeni. (c) Follout density ${ }^{90} \mathrm{Sr}$ after 5 days of the release from CNPP. Concentration of ${ }^{90} \mathrm{Sr}$ at the mouth of the canal CNPP-Constanta (d) and at the mouth of the Chilia Branch of the Danube Delta (e).

assessment of the efficiency of the actions planned to diminish the radiation exposure of the population via the aquatic pathways.

Acknowledgement. The research leading to these results has received funding from the European Atomic Energy Community Seventh Framework Programme FP7/2012-2013 under grant agreement 323287.

\section{References}

Bezhenar R., Heling R., Ievdin I., Iosjpe M., Maderich V., Willemsen S., de With G. (2016) Integration of marine food chain model POSEIDON in JRODOS and testing versus Fukushima data, Radioprotection 51 (HS2), S137-S139.

Cunge J.A., Holly Jr. F.M., Verwey A. (1980) Practical Aspects of Computational River Hydraulics. Pitman Publishing Ltd., London.

Heling R., Zheleznyak M., Raskob W., Popov A., Borodin R., Gofman D., Lyashenko G., Marinets A., Pokhil A., Shepeleva T., Tkalich P. (1997) Overview of the modelling of hydrological pathways in RODOS, Radiat. Prot. Dosim. 73 (1-4), 67-70.

Holly F.M., Yang J.C., Schovarz P., Scheefer J., Hsu S.H., Einhellig R. (1990) CHARIMA numerical simulation of unsteady water and sediment movements in multiply connected networks of mobilebed channels. IIHR Report No. 0343, The University of Iowa, Iowa City, Iowa, USA.

Ievdin I., Trybushny D., Zheleznyak M., Raskob W. (2010) RODOS re-engineering: aims and implementation details, Radioprotection 45 (5), 181-189.

Monte L., Periañez R., Kivva S., Laptev G., Angeli G., Barros H., Zheleznyak M. (2006) Assessment of state-of-the-art models for predicting the remobilisation of radionuclides following the flooding of heavily contaminated areas: the case of Pripyat River floodplain, J. Environ. Radioact. 88 (3), 267-288.

Zheleznyak M.J., Demchenko R.I., Khursin S.L., Kuzmenko Y.I., Tkalich P.V., Vitiuk N.Y. (1992) Mathematical modeling of radionuclide dispersion in the Pripyat-Dnieper aquatic system after the Chernobyl accident, Sci. Total Environ. 112 (1), 89-114.

Zheleznyak M.J., Tkalich P.V., Lyashenko G.B., Marinets A.V. (1993) Aquatic dispersion models-first approaches to integration into the CEC Decision Support System based on post-Chernobyl experience, Radiat. Prot. Dosim. 50 (2-4), 235-241.

Zheleznyak M., Potempski S., Bezhenar R., Boyko A., Ievdin I., Kadlubowski A., Trybushnyi D. (2010) Hydrological dispersion module of JRODOS: development and pilot implementation - the Vistula river basin, Radioprotection 45 (5), 113-122.

Cite this article as: M. Zheleznyak, S. Kivva, I. Ievdin, O. Boyko, P. Kolomiets, M. Sorokin, O. Mikhalskyi, D. Gheorghiu. Hydrological dispersion module of JRODOS: renewed chain of the emergency response models of radionuclide dispersion through watersheds and rivers. Radioprotection 51(HS2), S129-S131 (2016). 